Behavioural Sciences | Michiru Ito

\section{White identity in the Caribbean}

What does it mean to be white in a black majority population?
That's the question addressed That's the question addressed
in ongoing research into in ongoing research into
racial identity and ethnicity by Michiru Ito from Japan's Otsuma Women's University. Focusing on 'whiteness' Barbados and Trinidad, Ms Ito's work reveals substantial differences between the two islands in how people who identify as white perceive their heritage and place in modern post-colonial society. scientific statistical data to generalise who is white in Barbados and Trinidad, does provide insights, explanations, and pace for interpretation, to understand marginalised segment of Caribbea society - the white population."

\section{COLONIAL HISTORY}

Despite their similarities as former populations, Barbados and Trinidad have different racial demographics.

In Barbados around $92.3 \%$ of the population is black African-descended, $\bigvee \begin{aligned} & \text { hiteness studies - a subfield } \\ & \text { of racial studies - is an } \\ & \text { academic discipline which }\end{aligned}$ provides a new way of looking at race and ren the re 20 contur, there has so tar been histescarch ino how whitenss as a to understand societies in the Caribbean.

However, ongoing research by a Japanese academic into what it means to be white in black majority populations in the

Caribbean is producing valuable insights. Most importantly, it reveals that a sense of colonial superiority remains rooted in the minds of some white people, even
though younger generations try to deny though younger generations try to
the existence of white privilege.

Michiru Ito from Japan's Otsuma Women's University specifically examines what makes people consider themselves 'white' and different from non-white 'others' and what constiutes their whiteness in

Ms Ito's research is based on oral histories gathered by face-to-face interviews with who have lived there for more than three generations. She explained: "Although
Barbados developed as a British colony, Whour from Britain and the on convir. labour from Africa to work the sugar plantations established by settlers. Trinidad developed as a Spanish colony but was unable to attract enough Spanish settlers and offered incentives to people from other Catholic nations to settle there. Many of those who established Trinidad's sugar plantations, which also depended on slave labour from Africa, were from France. As a result, even though the island was surrendered to Britain in 1797 , Trinidad's society and culture contin to be governed by French morals $2.7 \%$ is white European-descended, and the remaining $5 \%$ is made up of people of Indian and Chinese origin. However, in Trinidad around $31.6 \%$ of the population is black African-descended, $37.1 \%$ is of Indian heritage, $0.7 \%$ is white t5.6\% other origins.

The differences in the islands' population groups can be explained by their colonia histories. Barbados and Trinidad were by Europeans who seized land from the native populations.

When slavery was abolished in the British Caribbean in 1834 and plantation owners required a new the islands was offered to people from other parts of the British Empie. Desperate to escape poverty at home, many of those who came to the Caribbean as indentured labourers were from India.

Although Barbados and Trinidad both gained independence in the 1960s,

Ms Ito's interviews reveal the ongoing impact of the islands' colonial history She explained: "While maintaining the concept of racial purity as white is difficult in the globalised Caribbe colonial notions of whiteness still remain. "In otherwords, many of and Trinidad are still taking ados of the idea of white supremacy in the $21^{\text {st }}$ century, which is derived from the historical and social significance of colonial 'race' relations in each island.

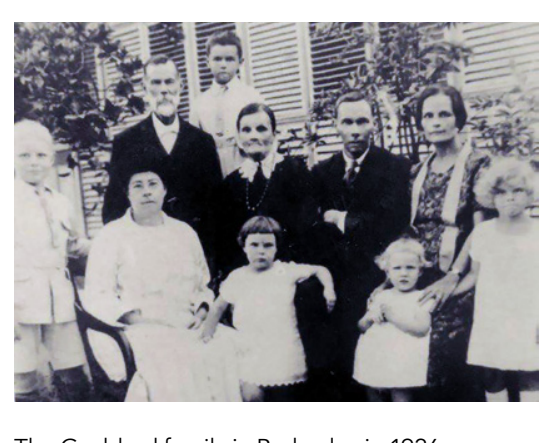

Fis:

JOSEPH BRIGGS MAYERS

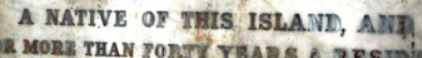

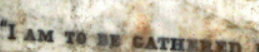

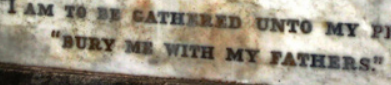

lrish name on a tomb
Church in Barbados.

Ms Ito's research therefore looks at who is considered white today, what constitutes their whiteness in relation to non-white others, and whether there are differences in that experience between the islands of Barbados and Trinidad.

Ms Ito has based her latest study on interviews carried out between 2016 and 2019 with 53 men and women 27 in Barbes live in Trinidad and 27 in Barbados. Aged 18 to 78 , all

who have lived on the islands for more than three generations.

BARBADOS INTERVIEWS In Barbados Ms Ito found that white people feel free to speak about their ethnicity and that 'whiteness' is a relative term. Even though they identify as European-descended white. some interviewees said that they Their construction of whiteness derives in part from their awareness

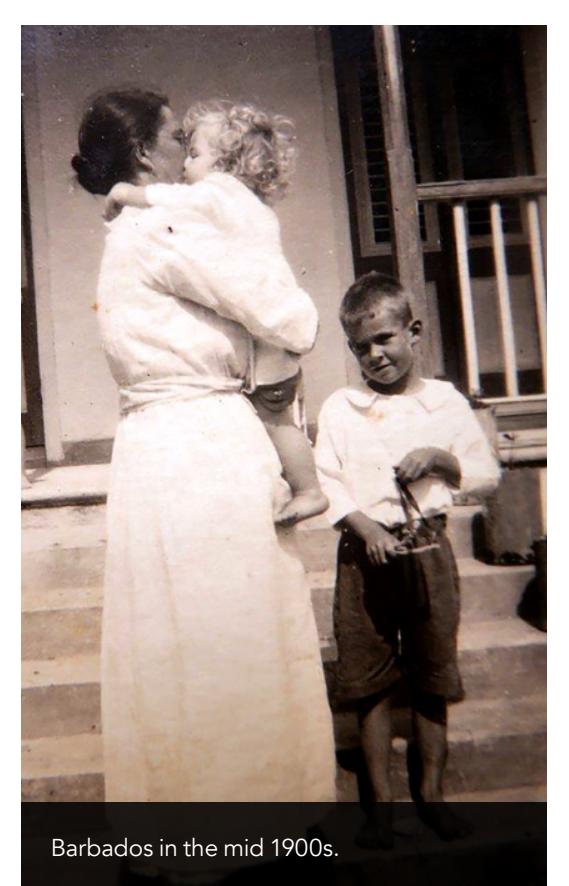

While maintaining the concept of racial purity as white is difficult in the globalised Caribbean, colonial notions of whiteness still remain in Barbados and Trinidad. of differences in physical features.
As one interviewee explained, they identify as white because they "look white, act white and belong to white society in Barbados". They also acknowledged that they might not e able to "pass as white" in Trinidad. Class is also an important part of white identity in Barbados. society is divided into groups according to income, education

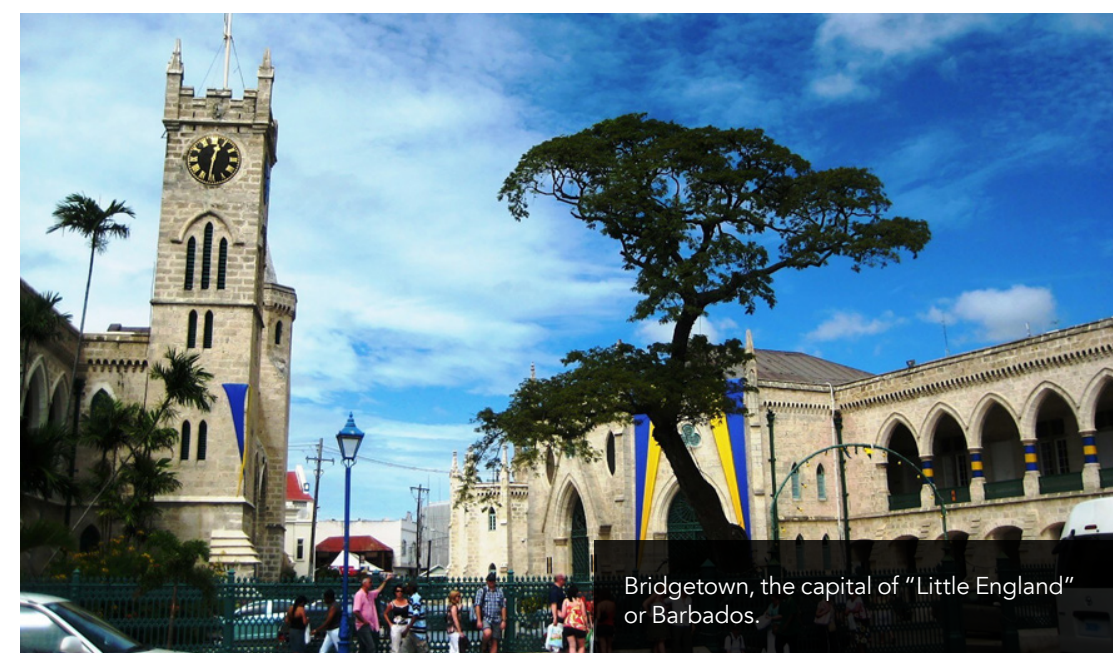




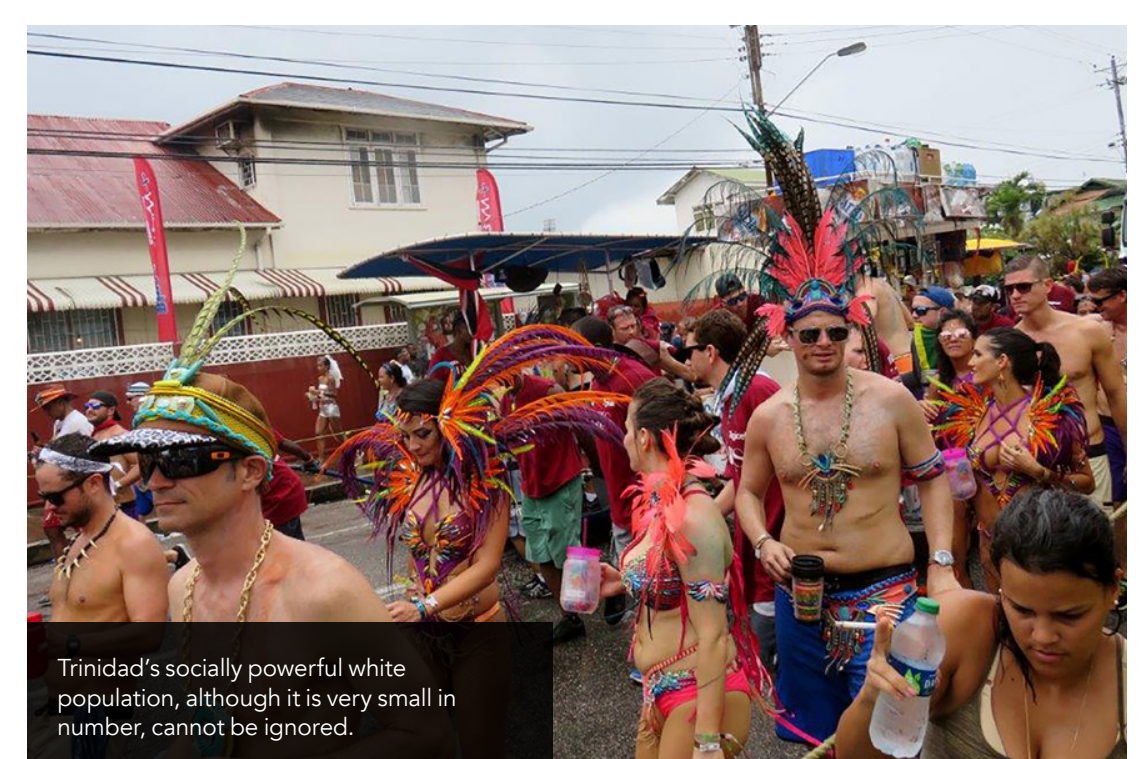

background, membership of religious and social groups and skin colour. Whiteness is not of itself sufficien to allow people entry into high society. Interviews with economically disadvantaged white people - the 'Poor White' descendants of Irish and English labourers transported that all Barbadians are now the same. They had the same jobs as Africandescended Barbadians and had no objections to interracial marriages.

White Barbadian interviewees of all ages said that they no longer believed in white supremacy or white of them enjoyed financially fortunate circumstances. On the contrary, som said hat besing white can make sore for example because white people

relationships, marriages and having that this was not the case in Tound Here, European-descend in Thidad. people, especially older people, place greater emphasis on 'racial purity'.

The interviews also revealed gender discrimination. Ms Ito explained: "For white males, having illegitima interracial children is one thing, but interracial marriage is another. For whi females, having interracial children and interracial marriage will directly lead them to be cut off from the family." In Trinidad interviewees of all age were even more insistent than those in Barbados on the importance of class as an indicator of white identity. example, olderinteriemplex. For a man of black African descent, of high class and with a good income may

As we enrich our understanding of whiteness in the Caribbean, our balanced understanding of the Caribbean will be fostered.

can sometimes be bullied by nonwhite 'others' based on the difference in their physical features and
'colonial sin' as slave own

\section{TRINIDAD INTERVIEWS}

still not be thought a suitable match for a white woman.

Younger interviewees said that white supremacy no longer exists in Trinidad to the Caribbean - revealed they felt privilege, although in reality many and that they don't abuse their their favour. For example, they are more with the police. They are also aware that whiteness signifies their ancestors therefore try to distance themselves from 'whiteness' in order to forge closer relationships with non-white 'others'.

However, Ms Ito's interviews suggest that older people in Trinidad do stil believe in white supremacy. One interviewee explained the complex power dynamic between white people and non-white employees. For example, she abhorred how some non-white domestic workers but explained that workers might not household gave them status.

\section{BALANCED UNDERSTANDING}

Ms Ito's research suggests that there are significant differences in the white identity between Barbados and Trinidad and between different age groups in the islands.

Most notably, while people who identify as white in Barbados said that white privilege no longer exists in Barbadian society, whites of European heritage regarded themselves as belonging to elite social groups in Trinidad. And while people of all ages no longer exists in the socremacy Barbados and Trinidad, that belief is not shared by Trinidad's older generations who have a much stronger insistence on racial purity.

It is unusual today for white people to speak so candidly about race and Ms Ito's insights into white identity in Barbados and Trinidad are a valuabl contribution to racial studies. She commented: "Caribbean whiteness is a product of the colonial experience diverse in their cultures and elements in societies depending on their colonial histories. As we enrich our Understanding of whicess in the of the Carb , our balanced understanding Irely to get a better job and to be historical roles as slave owners and will elderly white people mistreated their Trinidad said that whise people in and the Caribbean islands are

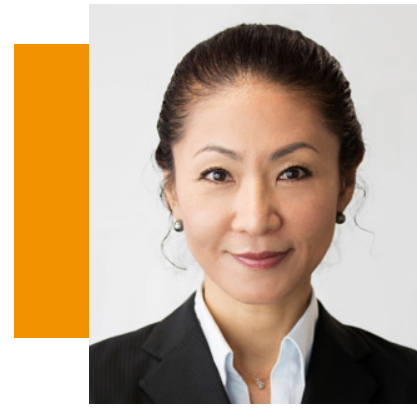

\section{Behind the Research} Michiru lto

E: ito.michiru@otsuma.ac.jp T: +81352756873 W: https://researchmap.jp/itomichiru
Research Objectives

Ms Ito examines white identity in the Caribbean.

\section{Detail}

Michiru lto

Otsuma Women's Univers

Chiyoda-ku

Chiyoda-ku

Japan

Bio

Michiru Ito is currently lecturing on Decolonized History, Caribbean Studies, British Imperialism and government and the United Nations in the field of diplomacy and socioeconomic development, and lived in Jamaica, Trinidad and Guyana for more than a decade.

\section{Funding}

MEXT KAKENH, Grant in Aid for Sciontific Research (C) (17K02034), Otsuma Grant-in Aid for Individual

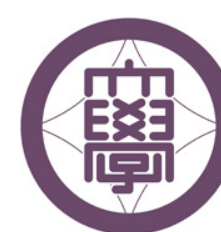

大妻女子大学

OTSUMA WOMEN'S UNIVERSITY instcolonial Experiences at Otsuma Women's University Exploratory Research (S3008)

\section{References}

Ito, M. (2019). Questioning Whiteness: Who is white? A case study of Barbados and Trinidad. International Journa of Human Culture Studies, 29, 129-137.

Ito, M. (2016). Constructing and Reproducing Whiteness. An oral history of French Creoles in Trinidad. 613-645.

\section{Personal Response}

Some of the interviews make uncomfortable reading in modern, post-colonial society,
especially when interviewees spoke candidly about topics such as 'racial purity'. Was there awareness among interviewees that some of their views are problematic?

IT Yes, there was. At the beginning of the interviews, many interviewees tended to avoid any racist remarks, some were offended, manipulative or disgraceful and then many insisted they were "pure white. people wish to voice the opinion that a certain 'race' is superior to others, because that argument is scientifically baseless and therefore considered unsophisticated. Nevertheless, what I tried to do was not to judge but to face the s, whom I trible realities have continued from the colonial days - and then to question what allowed them to continue in the postcolonial societies. Those might have been untouchable topics, but I believe I was successful in providing some insights to foster a balanced understanding of those whiteness, even though their stories
revealed that whiteness still works in

While white Barbadian interviewees 